\title{
Child Neurology: Mimics of cerebral sinovenous thrombosis
}

A pediatric case series

\author{
Elizabeth Kouzmitcheva, MD, FRCPC, Pradeep Krishnan, MD, FRCPC, Nomazulu Dlamini, MD, PhD, \\ Gabrielle deVeber, MD, FRCPC, Daune L. MacGregor, MD, DCH, MBA, FRCPC, and \\ Mahendranath Moharir, MD, MSc, FRACP
}

Neurology ${ }^{\circledR}$ 2018;91:e1545-e1548. doi:10.1212/WNL.0000000000006363

Cerebral sinovenous thrombosis (CSVT) is an uncommon but increasingly recognized condition in children because of greater clinical awareness and improvement in imaging techniques. ${ }^{1}$ Diagnosis is primarily radiologic. Clinical presentation is often nonspecific, including headache, vomiting, lethargy, cranial nerve 6th palsy, and neonatal seizures. ${ }^{1}$ Demonstration of an intraluminal filling defect and impairment of blood flow within the affected venous channel, with either magnetic resonance or CT venography (MRV or CTV), is generally considered sufficient to radiologically confirm thrombosis before initiation of anticoagulants. There are potential pitfalls in the interpretation of filling defects and flow disturbances on both MRV and $\mathrm{CTV}^{2,3}$ We present 3 cases diagnosed as CSVT with intraluminal filling defects and flow impairment in dural venous sinuses, which illustrate these potential pitfalls.

\section{Case 1}

A 9-year-old boy newly diagnosed with disseminated Burkitt lymphoma underwent neuroimaging to screen for CNS involvement before induction chemotherapy. He was completely asymptomatic from a neurologic perspective. Brain parenchyma was normal. Contrast-enhanced MRV revealed an intraluminal filling defect in the straight sinus with partial interruption of flow, increasing the suspicion of CSVT (figure). Stroke neurology consultation was initiated to advise if anticoagulant therapy was indicated. The MRI was carefully reviewed with a pediatric neuroradiologist. MRI signal intensity of a venous thrombus is believed to be because of changes in hemoglobin oxygenation and iron oxidation within red blood cells, with acute stage thrombus usually appearing isointense on T1-weighted and hypointense on T2-weighted imaging as described by Leach et al. ${ }^{4}$ In our patient, the intraluminal filling defect was isointense to gray matter on the T1- and T2-weighted images (figure, A and B) but with no definite blooming on the gradient echo (GRE) sequences within the lesion (figure, D). Blooming within thrombosed veins is a useful finding, which helps confirm the diagnosis of CSVT on GRE sequences. ${ }^{5}$ The filling defect demonstrated the presence of mild diffusion signal within the straight sinus, which can be seen with an acute thrombus and with cerebral metastasis (figure, C). Given the clinical history, the patient underwent whole-body PET $\mathrm{CT}$, which revealed a lesion in the straight sinus next to the confluence of the torcula with increased fluorodeoxyglucose uptake (figure, E). Eventually, the filling defect was determined to be a lymphomatous tumor deposit rather than a venous sinus thrombus, given the constellation of findings including fluorodeoxyglucose uptake on PET in the region of the torcula, absence of blooming on GRE, and isointense appearance to gray matter on T1- and T2-weighted imaging. The patient started induction chemotherapy and was not anticoagulated.

\section{Case 2}

A 5-year-old girl was diagnosed with left-sided otitis media and mastoiditis and admitted to a peripheral hospital for IV hydration and antibiotic therapy. Initial noncontrast MRI

\author{
Correspondence \\ Dr. Kouzmitcheva \\ elizabeth.kouzmitcheva@ \\ sickkids.ca
}

\footnotetext{
From the Division of Neurology (E.K., N.D., G.d., D.L.M., M.M.), Department of Pediatrics, and Department of Diagnostic Imaging (P.K.), the Hospital for Sick Children, University of Toronto, Ontario, Canada.

Go to Neurology.org/N for full disclosures. Funding information and disclosures deemed relevant by the authors, if any, are provided at the end of the article.
} 


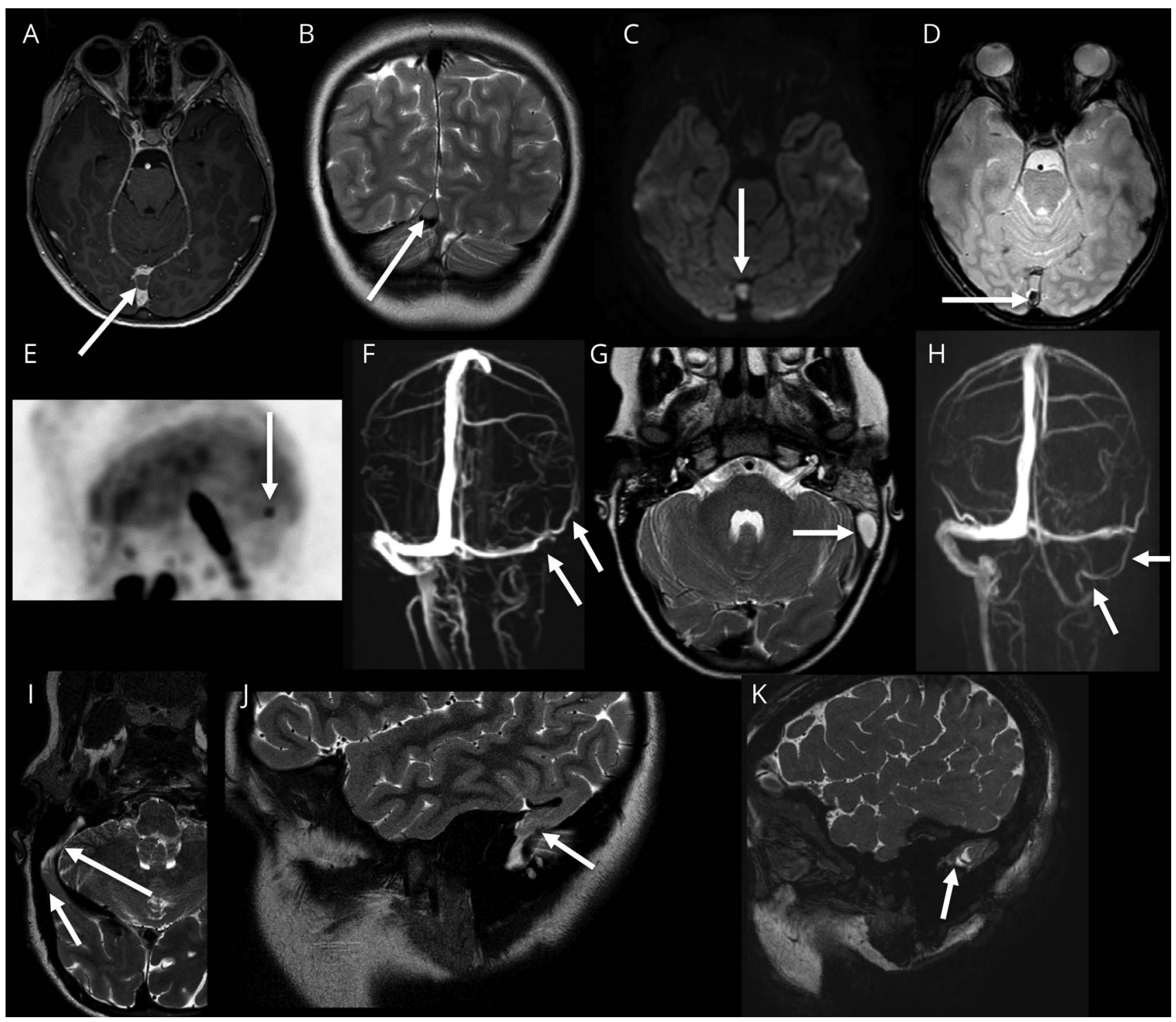

Case 1: (A) T1-weighted gadolinium-enhanced axial and (B) T2-weighted noncontrast coronal sequences demonstrating an intraluminal filling defect (arrows) within the dural leaves of the straight sinus. (C) Axial diffusion-weighted imaging. The filling defect demonstrates the presence of diffusion bright signal (arrow) within the straight sinus. (D) Axial multiplanar gradient echo imaging with no definite blooming seen (arrow). (E) Fluorodeoxyglucose uptake (arrow) on the PET in the region of the torcula. Case 2: (F) Time-of-flight magnetic resonance venography (MRV) shows abrupt cutoff of the left transverse sinus with a prominent left-sided vein of Labbe (arrow). (G) Axial T2-weighted sequence showing a left-sided posterior fossa extra-axial collection compressing the left sigmoid sinus. (H) Follow-up gadolinium MRV shows a hypoplastic left transverse and sigmoid sinus (arrow) with a small caliber left jugular vein (arrow). Case 3: (I) Oblique T2-weighted axial, (J) T2-weighted sagittal, and (K) fast field echo sagittal sequences demonstrating a short-segment dural defect (arrows) at the junction of the right transverse and sigmoid sinuses with a focal herniation of the right temporo-occipital lobe through the defect into the distal right transverse and proximal sigmoid sinuses.

reportedly demonstrated left-sided mastoiditis and a nonocclusive filling defect in the left sigmoid sinus. The filling defect was deemed to be a thrombus in the setting of otitis media, and after myringotomy and tympanostomy tube placement, enoxaparin was initiated and titrated to a therapeutic range. After discharge, she was continued on oral antibiotics for 2 weeks and referred to our institution for follow-up of the CSVT. Review of the outside neuroimaging revealed an abrupt cutoff of the left transverse sinus on the time-of-flight MRV (figure, F). A prominent left-sided vein of Labbe was seen, possibly providing collateral drainage to the left transverse sinus (figure, F). The MRV abnormality was considered to possibly represent a hypoplastic sinus rather than thrombosis. Follow-up contrast-enhanced MRV revealed normal flow through a hypoplastic left transverse and sigmoid sinus with an associated small lateral epidural abscess along the posterior mastoid margin (figure, $\mathrm{G}$ and $\mathrm{H}$ ). We concluded that there was no definitive evidence of CSVT and that the flow interruption and "occlusion" of the left transverse sinus were due to extrinsic compression from the epidural abscess. Enoxaparin was stopped. 


\section{Case 3}

A 17-year-old girl with Li-Fraumeni syndrome, a condition that predisposes carriers to cancer development, presented with increasing severity of chronic daily headaches. A contrast-enhanced MRI/MRV was ordered. She was diagnosed with right transverse and sigmoid sinus thrombosis, started on enoxaparin, and discharged home. Assessment by ophthalmology did not document any evidence of papilledema. The family contacted the treating neurologist to report worsening intensity of chronic daily headaches, episodic diplopia, dizziness, and presyncope 2 weeks after discharge. As a result, her imaging was reviewed at our interdisciplinary neurovascular rounds, in which an unusual finding of parenchymal brain herniation through a defect in the dura into the dural venous sinus was noted. Specifically, the temporooccipital gyrus was herniated into the right transversesigmoid junction (figure, I and J). The herniated brain tissue appeared gliotic. There was circumferential filling of the sigmoid sinus around a central filling defect without obstruction of venous outflow, except at the point of entry (figure, I and J). The herniation appeared similar to an encephalocele but only of the dura and without passing through the calvarium. Because there was no evidence of microhemorrhage on bloodsensitive sequences, it was concluded that the endothelium of the venous sinus remained intact (figure, $\mathrm{K}$ ). On review of our patient's MRI, congestion of the tentorium was noted on the right with more prominent right-sided veins. Flattening of the pituitary and low-lying cerebellar tonsils, not meeting the diagnostic criteria for Chiari type I, were also noted in retrospect. There was no further neuroimaging evidence of increased intracranial pressure, although the flattened pituitary and full-appearing optic sheaths, and the patient's symptoms increased suspicion for pseudotumor cerebri. The distended appearance of the torcula and the right transverse sinus suggested that this had not occurred acutely and increased the possibility of a broader connective tissue disorder. There was consensus that the right transverse and sigmoid sinus filling defect retrospectively never represented thrombosis. It was agreed that enoxaparin should be stopped. With regard to the patient's symptoms, a more detailed headache history and a lumbar puncture documenting a normal opening pressure confirmed a diagnosis of chronic daily headaches. She was started on a headache hygiene protocol and nutraceuticals.

\section{Discussion}

We report 3 cases that radiologically mimic CSVT. They highlight the importance of careful consideration of physiologic and pathologic conditions that may have radiologic appearances similar to CSVT to avoid potentially unnecessary and risky anticoagulant therapy.

On reviewing cerebral venous anatomy in children using MRV, it is important to recognize several potential pitfalls. These pitfalls may be subtle and include flow-related artifacts, which may mimic sinus thrombosis, variants of normal venous anatomy such as sinus hypoplasia or atresia, extra-axial collections causing external compression, normal intraluminal filling defects including arachnoid granulations and trabeculations, and rarer intraluminal filling defects such as tumor deposits and brain parenchymal herniation. Perhaps the most common cause of misdiagnosis of CSVT is related to asymmetry of the transverse sinuses, with the left being hypoplastic relative to the right $50 \%-60 \%$ of the time. Codominance is seen in $20 \%-25 \%$ of the population. ${ }^{2}$ Variable appearance of thrombus at various ages on different MRI pulse sequences is related to alterations in hemoglobin oxidation, which can often be helpful in differentiating a thrombus from its mimic. Table 2 published by Bracken et al. ${ }^{3}$ serves as a helpful reference in delineating thrombus appearance at each stage, although overlap often exists. ${ }^{3}$ Extra-axial fluid collections may mimic thrombus within a venous sinus, but it is important to keep in mind that they may also coexist with true thrombus, particularly associated with infections of the head and neck. ${ }^{3}$ Differentiating CSVT from extra-axial collections may be facilitated by administration of gadolinium contrast and various postprocessing techniques applied by an experienced neuroradiologist. ${ }^{3}$ Normal small filling defects, called arachnoid granulations, which are protrusions of arachnoid through the dura mater, are increasingly being visualized with higherresolution MRV imaging techniques. Arachnoid granulations provide CSF drainage from the subarachnoid spaces into the bloodstream. Several features can distinguish arachnoid granulations from CSVT including their shape and location, commonly seen in the superior sagittal and transverse sinuses, and their signal intensity on MRI, which is identical to CSF. ${ }^{3}$ Recently described brain parenchymal herniations into a dural venous sinus are exceedingly rare and controversial in their significance and associated symptoms. ${ }^{6}$ On review of recently reported similar cases in the literature, the transverse sinus appears to be the most common site of brain herniation into a venous sinus, with a reported incidence of $0.32 \%{ }^{6,7}$ Progressive headache has not been reported to be significantly associated with herniation, but was a common complaint, triggering neuroimaging in this cohort of patients. Brain herniations into dural venous sinuses are believed to develop because of expansion of arachnoid granulations in areas of dural weakness by ongoing CSF pulsation. ${ }^{6}$ As a result, they are rarer in children and more common with advancing age. ${ }^{7}$

In conclusion, imaging of pediatric CSVT remains challenging with numerous pitfalls. Knowledge of these pitfalls is important because it allows establishment of a broader differential diagnosis and accurate diagnosis or exclusion of CSVT with the help of an experienced neuroradiologist and various neuroimaging techniques.

\section{Author contributions}

E. Kouzmitcheva and P. Krishnan: drafting and revising the manuscript. N. Dlamini, G. deVeber, and D.L. MacGregor: revising the manuscript. M. Moharir: conceptualizing the idea for the manuscript and revising the manuscript. 


\section{Study funding}

No targeted funding reported.

\section{Disclosure}

The authors report no disclosures relevant to the manuscript. Go to Neurology.org/ $\mathrm{N}$ for full disclosures.

\section{References}

1. Ichord R. Cerebral sinovenous thrombosis. Front Pediatr 2017;5:163.
2. Widjaja E, Griffiths PD. Intracranial MR venography in children: normal anatomy and variations. AJNR Am J Neuroradiol 2004;25:1557-1562.

3. Bracken J, Barnacle A, Ditchfield M. Potential pitfalls in imaging of paediatric cerebral sinovenous thrombosis. Pediatr Radiol 2013;43:219-231.

4. Leach JL, Strub WM, Gaskill-Shipley MF. Cerebral venous thrombus signal intensity and susceptibility effects on gradient recalled-echo MR imaging. AJNR Am J Neuroradiol 2007;28:940-945.

5. Chiewvit P, Piyapittayanan S, Poungvarin N. Cerebral venous thrombosis: diagnosis dilemma. Neurol Int 2011;3:e13.

6. Battal B, Castillo M. Brain herniations into the dural venous sinuses or calvarium: MRI of a recently recognized entity. Neuroradiol J 2014;27:55-62.

7. Sampaio L, Dias da Costa JM, Rocha R, Leao M. Brain herniation into the dural venous sinus. J Pediatr 2016;174:276. 


\section{Neurology}

Child Neurology: Mimics of cerebral sinovenous thrombosis: A pediatric case series Elizabeth Kouzmitcheva, Pradeep Krishnan, Nomazulu Dlamini, et al. Neurology 2018;91;e1545-e1548

DOI 10.1212/WNL.0000000000006363

This information is current as of October 15, 2018

\section{Updated Information \&} Services

References

Subspecialty Collections

Permissions \& Licensing

Reprints including high resolution figures, can be found at: http://n.neurology.org/content/91/16/e1545.full

This article cites 7 articles, 1 of which you can access for free at: http://n.neurology.org/content/91/16/e1545.full\#ref-list-1

This article, along with others on similar topics, appears in the following collection(s):

Cerebral venous thrombosis

http://n.neurology.org/cgi/collection/cerebral_venous_thrombosis Childhood stroke

http://n.neurology.org/cgi/collection/childhood_stroke

\section{CT}

http://n.neurology.org/cgi/collection/ct

\section{MRI}

http://n.neurology.org/cgi/collection/mri

Pediatric stroke; see Cerebrovascular Disease/ Childhood stroke $\mathrm{http} / / / \mathrm{n}$.neurology.org/cgi/collection/pediatric_stroke_see_cerebrovasc ular_disease-childhood_stroke

Information about reproducing this article in parts (figures,tables) or in its entirety can be found online at:

http://www.neurology.org/about/about_the_journal\#permissions

Information about ordering reprints can be found online:

http://n.neurology.org/subscribers/advertise

Neurology ${ }^{\circledR}$ is the official journal of the American Academy of Neurology. Published continuously since 1951, it is now a weekly with 48 issues per year. Copyright @ 2018 American Academy of Neurology. All rights reserved. Print ISSN: 0028-3878. Online ISSN: 1526-632X.

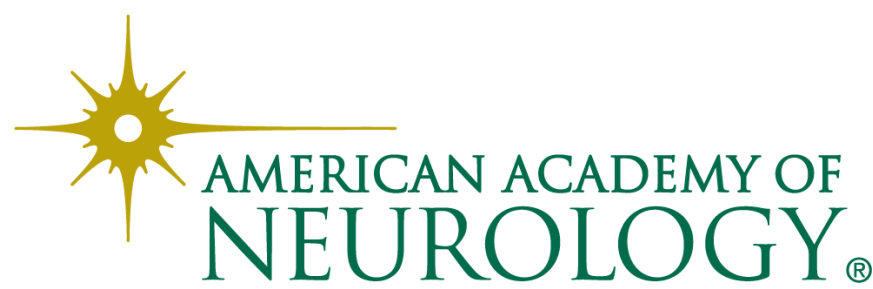

